\title{
NEGLIGENCE OF WOMEN HEALTH IN INDIA:ROLE OF GENDER BIASNESS AND OTHER SOCIO-CULTURAL ISSUES
}

\section{Shipra Shukla}

Research Scholar, Department of Social Work, University of Lucknow, Lucknow-226007

\begin{abstract}
Article DOI URL: https://doi.org/10.36713/epra3442

Women health is one of most neglected issues in developing countries like India. Though in past few years there has increase in awareness about rights of women and their health issues still we have long way to go. This paper talks the status of women health in India and how they are unaware about their health and facilities they can acquire to improve on their health. The women of India are not much concerned about their health; either we talk about physical health or mental health. In this paper, I have also discussed about different socio-cultural causes that led to this condition of women health, specially the role that gender biasness plays in poor condition of women health. This paper also talks about how such issues can be addressed and resolved.
\end{abstract}

KEYWORDS: developing, mental health, socio-cultural issues, gender biasness

\section{INTRODUCTION}

Women health has undergone high negligence since decades. Though worshipped like a goddess, the plight of a female becomes obvious if attention is drawn towards the suboptimal level of her health status. Little or no attention is drawn, when it comes to the maintenance of her physical, mental and psychological fitness.

One of the major causes towards degradation of women health in Indian society is gender biasness and inequality. From lower socio-economic strata of society to affluent and educated families, gender biasness can be seen in one or other forms. Within the clutches of inequality,a woman can rarely focus on her health. India has witnessed male favouritism since time immemorial- be it in terms of nutrition, education or basic human rights. Why a male is the one expected to earn for livelihood and a female termed a homemaker.

Innumerable atrocious cultural and traditional customs have been practiced in this patriarchal society against the female. Even after the abolishment of sati pratha and legal acceptance of women education and widow remarriage and other similar measures, there are still several practices which hamper women health such as unhealthy menstrual practices.

Pressurised under the burden of household obligations, females ignore their health and end up being afflicted with diseases like anaemia due to improper nutrition; sexually transmitted diseases (STDs like syphilis and gonorrhoea) due to lack of sex education; or typhoid and cholera due to improper sanitation. Majority of the females suffer from urinary tract infections (UTIs) due to lack of awareness about sanitary practices. Even the mental health of females suffers a major setback in a society which entraps them within four walls. Psychological diseases like depression and bipolar disorders become very common in adolescent and young adult females in such a scenario.

Major issue of concern is that the females and their families are not even aware of their ill health. Government has taken various steps and launched various schemes to improve women health in the country. But the women and their families are neither aware of these schemes and measures, nor of their constitutional rights. Thus it becomes very necessary for the society and mainly the women to become aware of their right to equality and also the measures taken by the government towards the betterment of their health. They should undergo routine health check-ups and serious treatment of all sorts of diseases without any feminine hesitation. A healthy female will give birth to healthy infants and will play her role in nation building.

\section{PRESENT STATUS OF WOMEN HEALTH IN INDIA}

India has seen a radical change in most spheres of living standards. Constant urbanisation, modernisation has rationalised mind-sets of individuals and brought in various reforms. However, the unfortunate situation of women health has seen no noticeable alterations.

According to WHO, "Health is defined as complete physical, mental and social wellbeing and not merely absence of disease. "According to the definition the present status of women health can be studied under the following heads- 


\section{PHYSICAL HEALTH}

As per the datafrom the Global Burden of Disease (GBD) among Indian women the deaths due to communicable, maternal, neonatal and reproductive diseases had decreased from $53 \%$ in 1990 to less than $30 \%$ in 2013 , on the other hand the percentage of deaths due to NCDs(non-communicable diseases) in women has moved up from $38 \%$ to $60.3 \%$. Some of the prevalent NCDs are: anaemia, cardiovascular disorders, diabetes,cancer and COPDs.

1. Anaemia- One of the major NCD afflicting Indian women is anemia mainly due to monthly menstrual discharge and poor access to supplementation in majority of population. $53 \%$ of all women have anemia as per the National Family Health Survey 2015-2016. The disease is of great concern, and the 2017 National Health Policy tabled by the Ministry of Health and Family Welfare, acknowledges this fact.Anaemia is defined as reduction in $\mathrm{RBC}$ count, haemoglobin concentration of blood or both, below normal. According to the World Health Organization (WHO), anaemia among women is defined as a haemoglobin concentration of $<120 \mathrm{~g} / \mathrm{L}$ for non-pregnant women aged 15 years and above, and a haemoglobin concentration of $<110-\mathrm{g} / \mathrm{L}$ for pregnant women. Anaemia can be etiologically classified ashaemolyticaneamia, haemorrhagicanaemia, anaemia due to nutritional deficiencies (like iron deficiency anaemia) and anaemia due to chronic disorders like diabetes mellitus. Out of these iron deficiency anaemia is most common amongst female population in India.

2. Cancer- statistical studies show that women are diagnosed with cancer in major proportion than men. According to a recently released World Cancer Report, 5.37 lakh Indian women were diagnosed with cancer in 2012, as compared to 4.77 lakh men. In yet another report titled Call for Action) a: Expanding cancer care for women in India, 2017, (an article by Times of India) cancer among women was estimated at 0.7 million, thus accounting for third highest cancer cases among women, after China and the US. The main cancers affecting female population are breast cancer, cervical cancer and Ovarian and uterine cancer.As per the data by National Institute of Cancer Prevention and Research, Noidain India in every eight minutes one woman dies of cervical cancer. The average age of breast cancer in India is almost a decade lower than in the West. One in two women in India who has been diagnosed with breast cancer die. A report released by E\&Y in association with industry body FICCI in 2017 titled 'Call for Action: Expanding Cancer Care for Women in India, 2017', mentioned that cervical and breast cancer rates in India were among the highest in the world. India also recorded the second highest cases of ovarian cancer globally. The report said that of the 2,000 women detected with cancer, 1,200 were diagnosed at a late stage. This means it reduces the first-year survival rate by 3 to 17 times for breast and cervical cancer. 3. Diabetes-According to the International Diabetes Federation (IDF), one in 10 women are living with diabetes, many of whom do not have access to healthcare and lack awareness about the disease. Gestational diabetes is also a major cause of concern among pregnant ladies. The majority of the women miss lab screening being caught up in regular household.

\section{MATERNAL HEALTH}

Though there has been tremendous growth over the last two decades in India, still maternal mortality remains persistently high in comparison to many developing countries. Out of all maternal deaths between 1992 to 2006 in the world, India contributed to $20 \%$.Factors responsible for high maternal mortality rates are often associated with utilization of antenatal care (ANC) prior to and during childbirth. Obstacles in attaining care includes delay in the decision for seeking care, coming at a medical institution, and allocation of quality care. The decision of seeking care depends upon the independence and empowerment factor; women who are more actively involved in decision-making processes of their families are able to opt for utilizing maternal care resources. The result is antenatal care utilization is lower for women of joint families and from Muslim families.Sometimes it is also directed in way by customs in our society that maternal care is inessential.

\section{CARDIOVASCULAR HEALTH}

Due to less access to healthcare services women in India have higher mortality rates relating to cardiovascular disease than men. One factor for the differing rates of attain stems from social and cultural norms which barricade women from accessing appropriate care. For instance, it was found that among patients with congenital heart disease, women were less likely to be operated on than men as their families are has this fear that this will make women less marriageable.

Mental health-Mental health problems in women is very common diseases in developing countries like countries like India due to factors like gender biasness, violence against women, awareness etc. According to WHO report 2001-

- About $47.9 \%$ women have depressive disorders in comparison to men who contribute to $29.3 \%$.

- Major mental health problems of the elder persons are depression, organic brain syndromes, and dementias and majority are women

- Among 50 million people who have faced violent conflicts, civil wars, disasters, and displacement, as much as $80 \%$ are women and children

- Violence against women ranges from $16 \%$ to $50 \%$ if we check the lifetime prevalence rate.

- Rape or attempted rape is suffered by at least one in five women in their lifetime.

\section{HIGH DEGREE OF NEGLIGENCE AMONG WOMEN THEMSELVES}

Though women in India today might be very much aware about health and well-being of her family and children still she rarely finds time for herself.According to GOQ India fit report 2018 (Indiafit.org) released recently "men are more aware about leading a healthy lifestyle than women. Their step count and water intake is more than women. Women have more illnesses and digestive disorders than men. Though women are conscious about being healthy, still they often neglect their own. It is being witnessed that women are more likely to have iron deficiency Anemia than men. As per the India Fit report' 18 , awareness regarding women health has is a burning issue in the Indian society today.

Women have now dual role- that of homemaker of the family and that of an employee in the workforce. As they are busy in their multiples duties and roles at home and workplace they often ignore routine health check-ups, unless the situation worsens. In India men are still given more importance in family and are considered as bread earners. Apollo Munich Health insurance conducted a survey in 19 cities in collaboration with Nielsen India Pvt. Ltd., in which it is found that only a few women are coming forward to buy health insurance even though number of women claiming for health insurance has 
risen. Due to less awareness for the need of health cover among women, they opting for products specially made for them has decreased.

The survey showed that more than $80 \%$ of men and women polled believe that the bread earner should be the first to be insured against life and health related risks. As India continues to fight for gender parity and seeks more women friendly policies, it is sad that we are unable to break mindsets when it comes to the bread earner of the family. When surveyed, 2,000 out of the 2,284 people feel that the man is the main bread winner in a family.

It is disheartening to see that inspiteof many years of independence, still women who ignore their health and still don't focus on areas like health insurance. Women give low priority to their health across India - in rural, suburban and urban areas. Lack of awareness of the ailmentsor just ignoring a problem and postponing medical intervention further adds to the issues of health

Gender has a makeable effect on health, as a result of both biological and gender-related differences. Due to the reason that in many societies, women and girlsare disadvantaged by discrimination rooted in socio-cultural factors their health is of particular concern. For example, women and girls face more risk to HIV/AIDS.

\section{ROLE OF GENDER BIASNESS}

As per The World Economic Forum, India is one of the worst countries in the world with regards to gender inequality. The 2011 Programmer's Human Development Report shows India at 132th position out of 187 in terms of Gender Inequality.The numerous factors by which GII (Gender Inequality Index) is calculated are maternal mortality rate, adolescent fertility rate, educational achievement and labour force participation rate. Gender inequality in India shows the women's lower chances of being literate, continuing their education and participating in the labor force.

Among the main determinants of healthwhich include social, economic, and political factors, gender is a social determinant which plays a major role in the women's health and their access to healthcare in India. Thus, the health of women is negatively affected by the high level of gender inequality in India. Studies show that girls are less likely to receive treatment from health care facilities compared to boys, when controlled for SES status.

The major role which gender has in health care access can be witnessedby checking the household and public sphere resource allocation. In India discrimination based on gender starts even before birth; female fetusis more likely to be aborted. If it is not aborted, due to her family's pressure for having a son the mother's pregnancy can be a stressful experience. Once born, especially in a family that already has many girls, daughters are likely to being fed less than sons. As females enter intoadulthood, due to their low status in Indian societywomen face many barriersthat prevent them from achieving equitable levels of health stem, especially in the rural and those areas which are poverty-affected.

Many cultural norms contribute to the low status and the discrimination against women in India. Patriarchy, hierarchy and multigenerational families are the societal barriers contributing to Indian gender roles. Men are more privileged and have got superior rights in Indiawhich results in a society that leaves women with little to no power. Women's low participation national parliament and the labor force in India very well illustrates this societal structure.
Marriage obligations is one of reasons why women are seen to be less valuable in family. Even though dowry is illegal still prevalent system in India due to Indian cultural norms. A power structure that favors men in household formation is created due to the higher future financial burden of females in the family. In addition to this, women are often seen as not capable of taking care of parents in old age, this is also a reason why people prefer sons over daughters.

All in all,men are considered to be more valuable for the family than women. Women face a different kind of gender discrimination due to their low participation in the public sphere as represented by the labor and political participation rates and the stigma of being less valuable in the family.

Gender inequalities, in turn, are directly linked to poor health outcomes of women. So many studies have shown that women visiting to hospital and their admission rates in hospital are lesser than men. This difference is seen in healthcare access because women usually are given lower share of household resources and thus healthcare resourcesutilized by women is seen lesser than men. In addition, it has been seen that women in India frequently underreport illnesses.

The cultural norms and gender expectations within the household are the major reason of this under reporting of illness among females of the family. Even the use of antenatal care and utilization of immunizations seen affected by gender discrimination. A study in Choi in 2006 found that in rural areas girls are less likely to get immunized than boys. This finding has led researchers to consider that different levels of health care being administered in rural areas is greatly influenced by the gender of the child. The gender factoris also associated with mobility. In India travelling in public spaces is more troublesome for women than men, which in turn results in greater difficulty to access services.

\section{SOCIO-CULTURAL BARRICADES AGAINST WOMEN HEALTH}

There are many socio-cultural factors that are barricade women and girls in India to access quality health services and achieve the best possible level of health:

1. Biased gender roles in Indian Society

2. Conservative orthodox customs

3. Lack of education and employment opportunities

4. Lack of awareness

5. Lack of women-centric health services

6. Unequal power relationships between men and women

7. An exclusive focus on women reproductive roles

\section{Biased gender roles in Indian Society}

India is a patriarchal society. Even though in present time women have started earning still men are considered to have the role of bread-earners and women to have role of homemaker. The result of this is that women have to bear dual roles. They have to work out and also the responsibility of household chores and children is on them. They do not get time for themselves in turn they ignore their own health. Women of the family are first one to wake in the morning and last one to sleep. Due to lack of proper sleep they often get many stress-anxiety disorders. A good woman in India is one who eats after the whole family has consumed the food and so they often eat whatever is left after all family members have eaten. The result of this is that most women in India are malnourished. According to National Family Health Survey 2015-2016, 53\% of all women have Anemia. 


\section{Conservative orthodox customs}

Though India has advanced in many fields and many of the orthodox customs been abolished and laws have been formed against them still in practice they are still prevalent -

- Child Marriage-Even though the Government of India enacted Prevention of Child marriage Act 2006 by replacing the earlier legislation of Child Marriage Restraint Act 1929 still it prevalent in many parts of India. $27 \%$ of girls in India are married before their 18 th birthday and $7 \%$ are married before the age of 15.According to UNCIEF, India has the highest absolute number of child brides in the world $-15,509,000$.Getting married at an early age effects on girls' health: increased risk for sexually transmitted diseases, malnourishment, cervical cancer, death during childbirth, and obstetric fistulas. Also the girl with poor health gives birth to unhealthy babies.

- Purdah System

Women in rural areas in India still follow purdah system. Modesty and shame is considered as ornaments of women in India. Such mindsets limi the women inside the four walls of house. This often is a great barrier to attain health services by women in India.

- Pathetic condition of widows in India

Though many mal-practices against widows like sati pratha is abolished in India but still their condition is not pathetic. In many parts of India people shun widows. They often have to lead lonely and pitiful life after their husband's death. They are discriminated often left to live alone in isolation. This affects their physical and mental health greatly.

- Menstruation taboos in India-

In many parts of country menstruation is considered ritually unclean. It is a topic of embarrassment and could not be discussed in public. So, women often are unaware of menstruation hygiene and do not discuss problems related to it. This effects their health adversely.

\section{Lack of education and employment} opportunities

Due to many factors like conservative mindset, coeducation, being useful for domestic chores, crime against women, girls are not send to school or even if they are somehow complete their basic education they are not given the equal opportunity as males. Due to the reason that dowry system is still prevalent in Indian society parents consider not spending more money on girl' s education rather considers saving it for her marriage. The result is that most women are dependent economically on their husbands. And as the men are the bread earner of family their health is considered more important.

Though for both genders poverty is a major obstacle to positive health outcomes, still on women and girls'healthis more affected due to the burden of multiple roles in family, for example, malnutrition due unhealthy feeding practices and Chronic obstructive pulmonary disease due use of unsafe cooking fuels.

\section{Lack of Awareness}

Women in rural and even in some urban parts of India are limited to four walls of the house. So, they are not aware of different health issues and health services by government which they can take benefit of. As it has been rightly said awareness is the key to prevention of diseases, this greatly affects their overall health.

\section{Lack of Women-centric health services}

The problem with healthcare system in India is that two-thirds of health workers are male especially in rural areas where it is found that only $6 \%$ of all doctors are female. So, women hesitate in going to doctors in case of health problems and consider treating most of problems at home or by taking medicines all by themselves without consulting a doctor, in fact mostly ignore their health.

\section{Unequal power relationships between men and women}

India being a patriarchal society, more power is in hands of man of the house. His takes all the decision in the family. His health is given more importance then female partner because mostly all the members of the family are dependent on him. Also, many a times it's been observed that women face physical, emotional and sexual violence by their male partners. This also affects their physical, mental and reproductive health.

\section{An exclusive focus on women's reproductive} roles

Though women have multiple roles still giving birth is considered as one most important roles in a patriarchal country like India. They are treated as machine to produce babies. Their reproductive health is not given due importance. They do not have right on their own bodies. They cannot take decisions whether they want to have a baby or not even if her body is not medically fit to do so. This affects her health physically as well as psychologically.

\section{PROPOSED MEASURES TO INCREASE AWARENESS AMONG WOMEN TOWARDS THEIR HEALTH}

Education and awareness is very important factor in promotion of health of women. Various steps can be taken for this-

$\checkmark \quad$ Multiple stakeholders must come forward to highlight the importance of screening and awareness to prevent health concerns as for many diseases prevention is said to be better than cure.

$\checkmark$ Because of dual role of women in today's times women often ignore a balanced diet which cause of Malnutrition and Anaemia. So, the organizations where they are working must take steps to organize health camps for spreading awareness about nutritional health.

$\checkmark$ Government should also organize heath awareness camps for women from time to time. It should also work towards making health care services more accessible to women.

$\checkmark \quad$ More female nurses, doctors and other healthcare workers must be appointed especially in rural areas so that women can come forward regarding their health issues.

$\checkmark \quad$ Bringing attention of academic organizations, policy makers, funding bodies and NGO's to developing an independent women's health researches.

$\checkmark$ NGO's, government and inter-governmental, funding agencies and cooperate bodies must broaden their focus including NCD's in women health.

$\checkmark$ Empowering and educating women to take charge of their own health and their families' health. 


\section{REFERENCES}

1. Badge, Vijay Loknath; Pandey, Minal; Solanki, Mridula J.; Shinde, Ratnendra Ramesh (2016). "A cross-sectional study of migrant women with reference to their antenatal care services utilization and delivery practices in an urban slum of Mumbai". Journal of Family Medicine and Primary Care. 5 (4): 759-764.

2. Haldar, Arpita (May 29, 2019). The need for Indian women to prioritise their health. The asian age.

3. Jha, Vivekanand (May 2016). The George Institute for Global Health India. Framing Women's Health Issues in 21st Century India - A Policy Report. Retrieved from https:// www.georgeinstitute.org/ sites/default/ files/ framing-wo mens-health-issues-in-21st-centuryindia.pdf

4. Matthews, Zoe. "Village in the City: Autonomy and Maternal Health-Seeking Among Slum Populations of Mumbai" (PDF). Collected Papers on Gender Using DHS Data: 69-92.

5. Pathak, Praveen (2010). "Economic Inequalities in Maternal Health Care: Prenatal Care and Skilled Birth Attendance in India, 1992-2006"
6. Pednekar, Mangesh; Gupta, Rajeev; et al. (2011). "Illiteracy, low educational status, and cardiovascular mortality in India". BMC Public Health. .

7. Rao, Mohan; Rao, Krishna (2011). "Human resources for health in India". Lancet. 377 (9765):587-98.

8. Thaddeus, S.; Maine, D. (July 1991). "Too far to walk: maternal mortality in context". Newsletter (Women's Global Network on Reproductive Rights) (36): 2224.

9. Women's A wareness and Attitude Towards Health A Big Disappointment. (2019). Retrieved from https:/ / nirogam.com/womens-health-findings/

10. World Health Organization. (2001). Gender disparities and mental health: The Facts.

11. Zeeshan, Nauseen. Women and Health issues in India. Retrieved fromhttps://womennow.in/womenhealth-issues-india/ 